\title{
OPTIMISATION OF PLATE THICKNESS USING FINITE DIFFERENCE METHOD
}

\author{
A. Agyei-Agyemang and P. Akangah \\ Department of Mechanical Engineering, \\ Kwame Nkrumah University of Science and Technology, Kumasi
}

\begin{abstract}
A finite difference numerical method of solving biharmonic equation is presented. The biharmonic equation and plate theory are used to solve a classical engineering problem involving the optimisation of plate thickness to minimise deformations and stresses in the plate. Matlab routines were developed to solve the resulting finite difference equations. The results from the finite difference method were compared with results obtained using ANSYS finite element formulation. Using the finite difference method, a plate thickness of $277 \mathrm{~mm}$ was obtained with a mesh size of $3 \mathrm{~m}$ and a plate thickness of $271 \mathrm{~mm}$ was obtained with a mesh size of $1 \mathrm{~m}$., whiles using ANSYS finite element formulation, a plate thickness of $270 \mathrm{~mm}$ was obtained. The significance of these results is that, by using off-the-shelf general application tool and without resorting to expensive dedicated application tool, simple engineering problems could be solved.
\end{abstract}

Keywords: Finite Difference (FD), Biharmonic Equation, Finite Element (FE), Plate Theory

\section{INTRODUCTION}

The objective of this work was to demonstrate the feasibility of solving biharmonic equation using off-the-shelf general application tools such as MATLAB. Most often, researchers and engineers in poor developing countries such as Ghana do not have access to dedicated and powerful application tools such as ANSYS to perform detailed engineering analysis. However, understanding the mathematical formulations of the required partial differential equation (PDE) and plate theory, researchers and engineers can use general application tools such as MATLAB to solve common engineering problems.

The three important steps taken to model the plate were (i) problem definition, (ii) mathematical model, and (iii) computer simulation (Peiro and Sherwin, 2005). In developing a mathematical model of the plate under investigation, a finite difference formulation was favoured because the PDE can easily be obtained in the strong form (Peiro and Sherwin, 2005). Also, because a simple rectangular geometry of the plate was considered, a finite difference formu- 
lation was favoured over a finite element formulation (Kelkar, 2006).

(Lau, 1978) has presented a method of using finite difference formulation for treating curvilinear boundary (Henwood et al., 1980) also presented a method of using FD formulation in predicting the elastic behaviour of rectangular plate on an elastic foundation. These approaches demonstrate the effectiveness of FD method in solving engineering problems.

\section{PROBLEM DEFINITION}

The problem under consideration was a plate of thickness $\mathrm{t}$ supported by a column and fixed at the sides labelled A, while sides labelled B were free as shown in Figure 1. It is assumed that a load of $\mathrm{P}_{\mathrm{z}} \mathrm{N} / \mathrm{m}^{2}$ acted uniformly on the surface of the plate. The objective was to find the required thickness of the plate such that the plate did not fail by stresses exceeding the allowable stress or by yielding.

The physical dimensions of the problem were:

$\mathrm{L}=60 \mathrm{~m} \times 60 \mathrm{~m}$;

$\mathrm{L}_{\mathrm{c}}=30 \mathrm{~m} \times 30 \mathrm{~m}$; (dimensions of the column)

Material yield stress $=310 \mathrm{MPa}$

Allowable deflection $=2 \%$ of hanging length $(15 \mathrm{~m})$, i.e. $0.30 \mathrm{~m}$.

The objective was to optimise the thickness $t$ for stress and deflection. In figure 2, the relevant boundary conditions of the problem were defined.

\section{MATHEMATICAL MODEL}

For plates of linearly elastic isotropic material, the deflection is described by the biharmonic PDE:

$$
\frac{\partial^{4} w}{\partial x^{4}}+2 \cdot \frac{\partial^{4} w}{\partial x^{2} \cdot \partial y^{2}}+\frac{\partial^{4} w}{\partial y^{4}}=\frac{P_{z}}{D}
$$

Where:

$w$ is the deflection

$P_{z}$ is the applied load per unit area

$D=\frac{E \cdot t^{3}}{12\left(1-v^{2}\right)}$; is the modulus of rigidity of the plate
$E$ is the Young's modulus of elasticity of the material

$v$ is the Poisson's ratio of the material

$t$ is the plate thickness

Using classical plate and shell theory (Ugural, 1999), the following formulae for the bending, twisting moments and shear force were obtained:

$$
\begin{gathered}
M_{x}=-D\left(\frac{\partial^{2} w}{\partial x^{2}}+v \frac{\partial^{2} w}{\partial y^{2}}\right) \\
M_{y}=-D\left(\frac{\partial^{2} w}{\partial y^{2}}+v \frac{\partial^{2} w}{\partial x^{2}}\right) \\
M_{x y}=-D(1-v) \frac{\partial^{2} w}{\partial x \partial y} \\
Q_{y}=-D \cdot\left(\frac{\partial}{\partial y}\left(\frac{\partial^{2} w}{\partial x^{2}}+\frac{\partial^{2} w}{\partial y^{2}}\right)\right)=-D \cdot \frac{\partial}{\partial y} \cdot \nabla^{2} w=0
\end{gathered}
$$

Eq. 1 can be written as (Ugural, 1999):

$\frac{\partial^{2} M_{x}}{\partial x^{2}}+2 \cdot \frac{\partial^{2} M_{x y}}{\partial x \cdot \partial y}+\frac{\partial^{2} M_{y}}{\partial y^{2}}=-P_{z}$

Using Eqs. 2, 3 and 4, Eq. 6 could also be rewritten as:

$$
\begin{gathered}
\frac{\partial^{2}}{\partial x^{2}}\left[D\left(\frac{\partial^{2} w}{\partial x^{2}}+v \cdot \frac{\partial^{2} w}{\partial y^{2}}\right)\right]+2(1-v) \frac{\partial^{2}}{\partial x \cdot \partial y}\left(D \frac{\partial^{2} w}{\partial x \cdot \partial y}\right)+\frac{\partial^{2}}{\partial y^{2}} \\
{\left[D\left(\frac{\partial^{2} w}{\partial y^{2}}+v \frac{\partial^{2} w}{\partial x^{2}}\right)\right]=P_{z}}
\end{gathered}
$$

Because of equal mesh along $\mathrm{x}$ - and $\mathrm{y}$-axes, i.e., $\partial x=\partial y=h$ Eqs. 7, 2, 3, and 4 could be written respectively as (after using the relevant stencils):

$$
A \cdot w=\frac{P_{z}}{D} \cdot h^{4}
$$


Where:

A is the deflection coefficient matrix $\mathrm{w}$ is the deflection vector

$$
\begin{aligned}
& M_{x}=-\frac{D}{h^{2}} \cdot C \cdot w \\
& M_{y}=-\frac{D}{h^{2}} \cdot E \cdot w \\
& M_{x y}=-\frac{D(1-v)}{4 \cdot h^{2}} \cdot F \cdot w
\end{aligned}
$$

Where:

$\mathrm{C}, \mathrm{E}$, and $\mathrm{F}$ are the moments' coefficient matrices along the $\mathrm{x}-, \mathrm{y}$ - and $\mathrm{xy}$-axes respectively $w$ is the deflection vector.

The principal moments and the maximum twisting moments (Ugural, 1999) are also given as:

$$
\begin{aligned}
& M_{1,2}=\frac{M_{x}+M_{y}}{2} \pm \sqrt{\left(\frac{M_{x}-M_{y}}{2}\right)^{2}+M_{x y}^{2}} \\
& \left(M_{x y}\right)_{\max }=\sqrt{\left(\frac{M_{x}-M_{y}}{2}\right)^{2}+M_{x y}^{2}}
\end{aligned}
$$

The principal stress matrices can be evaluated as (Ugural, 1999):

$$
\begin{aligned}
& \sigma_{1}=\frac{12 M_{1} \cdot z}{t^{3}} \\
& \sigma_{2}=\frac{12 M_{2} \cdot z}{t^{3}} \\
& \tau_{\text {max }}=\frac{12\left(M_{x y}\right)_{\text {max }} \cdot z}{t^{3}}
\end{aligned}
$$

Where:

$$
z= \pm \frac{t}{2}
$$

\section{COMPUTER SIMULATION}

Discretisation of Problem Domain

Using equal meshes along the $\mathrm{x}$ - and $\mathrm{y}$-axes, the mesh size $\mathrm{h}$ is given by:

$$
h=d x=d y=\frac{L}{n-1}
$$

The number of nodes, $\mathrm{n}$, along $\mathrm{x}$ - and $\mathrm{y}$-axes can be calculated as:

$$
n=\frac{L}{h}+1
$$

Data stored in a matrix will be represented in $n^{2}$ $\mathrm{x} \mathrm{n}^{2}$ matrix. To facilitate numerical modelling of the problem, uniform meshing was used.

Eq.s 2, 3, 4 and 7 were modelled using FD method. Stencils were developed for each PDE. Equation 5 was used in reducing the boundary conditions along the free-ends. However, because of space requirements, only the moment $\mathrm{PDE}$ along the $\mathrm{x}$-axis will be used to illustrate the method.

\section{Flow Chart of Program Events}

Figure 3 showed how the various program events were connected together. The coefficients for deflection and moments were calculated only once based on the relevant stencils.

\section{Finite Element Modelling}

The plate was modelled in ANSYS using SHELL63 rectangular element. This model acted as the baseline against which the FD method was evaluated.

\section{RESULTS AND DISCUSSION}

The results of the simulations were presented in Table 1.

By decreasing the mesh size from $3 \mathrm{~m}$ to $1 \mathrm{~m}$, the percentage error improved from $2.59 \%$ to $0.37 \%$.

For a mesh size of $3 \mathrm{~m}$, the errors in stress values were consistent and approached an average value of $34 \%$, also the errors in the deflection values were consistent and approached an averaged value of $5.4 \%$. 
Table 1: Comparison of results from Finite Element and Finite Difference Methods

\begin{tabular}{lccccc}
\hline Methods & $\begin{array}{c}\text { Maximum } \\
\text { Plate } \\
\text { Thickness } \\
(\mathrm{m})\end{array}$ & $\begin{array}{c}\text { \% error } \\
\text { (plate } \\
\text { thickness) }\end{array}$ & $\begin{array}{c}\text { Maximum } \\
\text { Plate } \\
\text { Deflection } \\
\text { (m) }\end{array}$ & $\begin{array}{c}\text { Maximum } \\
\text { stress } \\
\text { (MPa) }\end{array}$ & $\begin{array}{c}\text { \% error } \\
\text { (m aximum } \\
\text { stress) }\end{array}$ \\
\hline \hline FE & 0.270 & - & 0.2978 & 134.00 & - \\
FD (3 m mesh size) & 0.277 & $2.59 \%$ & 0.2982 & 88.00 & $34.33 \%$ \\
FD (1 m mesh size) & 0.271 & $0.37 \%$ & 0.2995 & 145.70 & $8.73 \%$ \\
\hline
\end{tabular}

For a mesh size of $1 \mathrm{~m}$, the errors in stress values were consistent and approached an average value of $8.8 \%$, also the errors in the deflection values were consistent and approached an average value of $0.58 \%$. From figures 6 and 7, it can be seen that the finer mesh size $(1 \mathrm{~m})$ is superior to the coarse mesh size $(3 \mathrm{~m})$ results showed in figures 4 and 5 .

For proper engineering design, the maximum plate thickness will have to vary across different cross-sections of the plate depending on the stresses on the plate. Using the stress matrices (equations 12, 13 and 14), the principal stresses at pre-determined locations were calculated using finite difference method. A $3 \mathrm{~m}$ mesh size was used; that is, node distribution of $21 \times 21$ on the plate (including area of supporting column). A MATLAB code was developed to do the necessary calculations. Figure 9 showed a 3-D plot of the maximum principal stresses across the surface of the plate. The critical points were at the fixed edges of the plate as expected, especially at the supporting column (edge A, see Figure 2), and the four corners of the plate. The maximum principal stress at the column support was $208.2 \mathrm{MPa}$ and that at the corner of the plate was $187.8 \mathrm{MPa}$. The least maximum principal stress was $0.16 \mathrm{MPa}$, recorded three (3) meters from the fixed edge (edge A, see Figure 2). Appropriate minimum thicknesses that could sup- port the plate were found using finite difference method. Figure 10 showed a 3-D plot of the minimum thicknesses across the surface of the plate. This could be the optimum values of the thickness of the plate, but it would not be practical to manufacture and use it, since there will be the introduction of stress concentration on the plate. The minimum thickness of the plate needed to support the plate were as follows: $0.243 \mathrm{~m}$ at the column support, $0.221 \mathrm{~m}$ at the corner of the plate and $0.053 \mathrm{~m}$ at the free edge.

Optimisation of the thickness of the plate would result in savings in terms of material used as well as in the use of lighter weight structure resulting in improved deflections at the free ends. Figure 8 showed the deflection of plate at the selected nodes. For ease of manufacture, the thicknesses at the various nodes could be adjusted upward to give a linear relationship and also to avoid the unwanted introduction of stress concentration spots on the plate. Figure 11 showed the improved plate thickness. The use of fillets at edges with sudden change in thickness could further improve the design. Figure 12 showed how a section through the centre line of the side with the free edges would look like.

\section{REFERENCE}

Henwood, D.J., Whiteman, J.R. and Yettram, A.L. (1980). Finite Difference Solution of A System of First-Order Partial Differential

138 Journal of Science and Technology, Vol. 28, No. 3, Dec., 2008 
Equations. International Journal for $\mathrm{Nu}$ merical Methods in Engineering, 17: 13851395.

Kelkar, A. (2006). Computational Methods Fall 2006, Graduate Course. NC A\&T State University, NC, USA.

Lau, P.C.M. (1978). Curvilinear Finite Difference Method for Biharmonic Equation. International Journal for Numerical Methods in Engineering, 14: 791-812.
Peiro, J and Sherwin, S. (2005). Finite Difference, Finite Element and Finite Volume Methods for Partial Differential Equations; Handbook of Materials Modelling, Springer, Netherlands, 2005; pp. 2424-2430.

Ugural, A.C. (1999). "Stresses in Plates and Shells". McGraw-Hill, NY. USA. pp. 78-84. 